\title{
Relationship Between Air Quality and the Number of Acute Respiratory Disease Infections in Mexico City
}

\author{
Owen Xu Li
}

xuliowen605@gmail.com

Senior High School Student, American School Foundation, Mexico City, 01120, Mexico

\begin{abstract}
In this study, an analysis of the daily averages of Nitrogen Dioxide and Tropospheric Ozone is done because they are produced mainly during or because of the combustion of fossil fuels. Two time periods were studied (January 1 to March 14, and March 15 to December 31) for 2019 and 2020 in order to determine the relationship between the regulatory measures imposed by the government to contain COVID-19 and acute respiratory diseases in Mexico City. Using Google Sheets's tools, the percentages of change in the atmospheric concentration for each pollutant in each period and year were calculated and then compared with the reduction in the number of infections from acute respiratory diseases in 2020 . The reduction of Nitrogen Dioxide was enough to conclude that the general air quality in Mexico City improved, which resulted in fewer people hospitalized for acute respiratory diseases in 2020 compared to 2019. So, a conclusion can be made that the contingency period caused by the recent COVID-19 pandemic resulted in a reduction in the atmospheric concentrations of the pollutants studied and in a reduction in the number of people hospitalized for acute respiratory diseases related to these pollutants.
\end{abstract}

Keywords: Pollution; Mexico City; COVID-19; Respiratory Diseases; Ozone; Nitrogen Dioxide

\section{Introduction}

COVID-19, better known as Coronavirus, was first transmitted to a human in late 2019 in the city of Wuhan in central China's Hubei Province (Shereen et al. 2020). On March 11, 2019, the World Health Organization (WHO) declared this contingency a pandemic; since then, it has spread to at least 171 countries, causing more than 3 million deaths and infecting more than 170 million inhabitants around the world [WHO 2021]. Due to its high risk and contagion rate, many governments have ordered large-scale self-isolation of their populations, implementing measures to reduce human contact as much as possible [BBC 2020]. Such restrictions have resulted in a decrease in vehicular and air traffic, and industrial activities, leading to improved air quality in some countries [Munoz et al. 2020; Gualtieri et al 2020; Mahato et al. 2020; Lian et al. 2020; Masum and Pal 2020]. So, a hypothesis was made that government-imposed restrictions in Mexico City would cause a reduction in the concentrations of Nitrogen Dioxide and Tropospheric Ozone and, consequently, a reduction in the number of people hospitalized for acute respiratory diseases, excluding COVID-19.

\section{Introduction to Nitrogen Dioxide $\left(\mathrm{NO}_{2}\right)$ and Tropospheric Ozone $\left(\mathrm{O}_{3}\right)$}

$\mathrm{NO}_{2}$

$\mathrm{NO}_{2}$ originates mainly from all vehicles that use a combustion engine. $\mathrm{NO}_{2}$ is the only nitrogen oxide (NOx) that is harmful to health, as it aggravates respiratory diseases such as bronchitis and causes irritation in the respiratory tract and lung cell wear. 
$\mathrm{O}_{3}$

$\mathrm{O}_{3}$ is a secondary pollutant that results from the reaction of Volatile Organic Compounds (VOCs), oxygen, and solar radiation. It is a strong oxidant that in high concentrations has negative impacts on health: irritation to the eyes and the respiratory tract, reducing respiratory function. Furthermore, there is a direct relationship between chronic ozone exposure and increased morbidity and mortality.

\section{Methodology}

This is a case study and primary sources were used. The exact procedure followed to develop the investigation is explained below.

First, data was collected from Mexico City's government's Atmospheric Monitoring Directorate. This study focuses on $\mathrm{NO}_{2}$ and $\mathrm{O}_{3}$. These pollutants are important factors in the greenhouse effect and affect the respiratory system. The time periods of January 1 to March 14 (before the quarantine) and March 15 to December 31 (during the quarantine) of 2020 were used to compare the atmospheric concentrations of the pollutants with the time periods from January 1 to March 14 and from March 15 to December 31 in 2019. Something important to note is that 2019 did not have February 29; the absence of this day is displayed as a cutoff on day 59 of all the graphs of the first time period analyzed.

Data of the hourly atmospheric concentrations of $\mathrm{NO}_{2}$ and $\mathrm{O}_{3}$ per station in Mexico City was collected from the Automatic Atmospheric Monitoring Network (RAMA, in Spanish) of the Atmospheric Monitoring Directorate of Mexico City's Government. Only the stations that had at least $75 \%$ information in both years were selected to be studied. Table 1 shows the stations that met the requirements. Afterwards, an hourly average of all the stations was calculated, ignoring the null values (values expressed as -99). Once the hourly averages were calculated, the following formulas were used in Google Sheets to calculate daily averages in Mexico City.

$$
\begin{gathered}
\text { '= AVERAGEIF (D2:AL2, " - } 99 ") \\
{ }^{2}=A V E R A G E I F(O F F S E T(\$ C \$ 2,(R O W()-R O W(\$ H \$ 2)) * 24,24,), ">-99 ")
\end{gathered}
$$

1 "AVERAGEIF" is the averaging function with a restriction. In this study's case, the restriction was to ignore null values. This is expressed as " $<>-99$ " in the equation. The $>$ symbol tells the function to only average values that are not equal to -99. D2: AL2 is the range of columns where the data to be averaged was located.

2 "AVERAGEIF" is the function to make averages with a restriction: to ignore the -99 (null) values. "OFFSET" is the function that returns a range reference shifted to a specified number of rows and columns from an initial cell reference. The parenthesis "(\$C\$2, $(\operatorname{ROW}()-\operatorname{ROW}(\$ H \$ 2)) * 24,, 24)$,$" indicates Google Sheets that it should start$ counting from cell $\mathrm{C} 2$ (where the hourly averages were placed) and that the results should be placed starting in cell H2. In the formula, the symbol "\$" is extremely important as it means that when executing the function, Google Sheets starts from the specified cell ( $\mathrm{C} 2$ and $\mathrm{H} 2)$ and does not automatically move to the next cell (C3 and H3). This way, the averages for one day are always the 24 rows after the 24 rows of the last day. The number 24 in the formula represents the number of rows to average each time the formula is run.

Table 1. RAMA monitoring stations with at least $75 \%$ information in 2019 and 2020 . Own elaboration with data

\begin{tabular}{|c|c|c|c|}
\hline Code & Name & City Hall or Municipality & Entity \\
\hline
\end{tabular}
from Mexico City's Atmospheric Monitoring Directorate. 


$\begin{array}{lccc}\text { CCA } & \text { Centro de Ciencias de la Atmósfera } & \text { Coyoacán } & \text { Mexico City } \\ \text { CUT } & \text { Cuautitlán } & \text { Tepotzotlán } & \text { State of Mexico } \\ \text { FAC } & \text { FES Acatlán } & \text { Naucalpan de Juárez } & \text { State of Mexico } \\ \text { FAR } & \text { FES Aragón } & \text { Nezahualcóyotl } & \text { State of Mexico } \\ \text { GAM } & \text { Gustavo A. Madero } & \text { Gustavo A. Madero } & \text { Mexico City } \\ \text { MER } & \text { Merced } & \text { Venustiano Carranza } & \text { Mexico City } \\ \text { MPA } & \text { Milpa Alta } & \text { Milpa Alta } & \text { Mexico City } \\ \text { MON } & \text { Montecillo } & \text { Texcoco } & \text { State of Mexico } \\ \text { NEZ } & \text { Nezahualcóyotl } & \text { Nezahualcóyotl } & \text { State of Mexico } \\ \text { SAG } & \text { San Agustín } & \text { Ecatepec de Morelos } & \text { State of Mexico } \\ \text { SFE } & \text { Santa Fe } & \text { Cuajimalpa de Morelos } & \text { Mexico City } \\ \text { TAH } & \text { Tláhuac } & \text { Xochimilco } & \text { Mexico City } \\ \text { TLA } & \text { Tlalnepantla } & \text { Tlalnepantla de Baz } & \text { State of Mexico } \\ \text { UIZ } & \text { UAM Iztapalapa } & \text { Iztapalapa } & \text { Mexico City } \\ \text { UAX } & \text { UAM Xochimilco } & \text { Coyoacán } & \text { Mexico City }\end{array}$

VIF

Villa de las Flores

Coacalco de Berriozábal State of Mexico

In order to calculate the percentage of change, Google Sheets's tools were employed to obtain the equation of the regression lines for each pollutant for each period of time analyzed. This was because in some graphs, the final and initial values were almost identical or extremely different due to varying concentrations. So using the regression line (in this case it represents the median) helped reduce the variation. The following formula was used to calculate the percentage of change:

$$
\% \text { change }=\frac{\text { final }- \text { initial }}{\text { initial }} * 100
$$

Something important to note is that in order to use the regression line - expressed in the form $y=m x+b$, where " $\mathrm{m}$ " is the slope and " $\mathrm{b}$ " is the intercept on the vertical axis - the values of "x" were substituted for the days that had passed. For example, since there were 73 days for 2019 and 74 for 2020 in the first time period analyzed from January 1 to March 14, "x" was substituted for 73 in 2019 and for 74 in 2020. Similarly, for the second period of March 15 to December 31, "x" was substituted for 291 for the two regression lines of 2019 and 2020, since they both had the same number of days. 
Once this process was completed, the investigation of the number of infections due to acute respiratory diseases in Mexico, excluding COVID-19, continued during this same period. Data was collected from the Epidemiological Bulletin of the Government of Mexico, which includes the accumulated number of infections of various viruses and bacteria throughout Mexico per week. Only the values of every 4 weeks in both 2019 and 2020 were used to have the same comparison procedure. As the focus of the study was Mexico City, only Table 5.1 on page 22 was used. Once the data was collected, the same to compare the pollutants was used: obtain the regression line with Google Sheets and calculate the percentage change of the 2020 and 2019 to compare.

Finally, a comparison of the percentage change in atmospheric concentrations of pollutants with the percentage change in the number of acute disease infections was made to establish correlation and causality.

\section{Results}

$4.1 \mathrm{NO}_{2}$

Daily averages of Nitrogen Dioxide in Mexico City from January 1st to March 14, 2020 and 2019

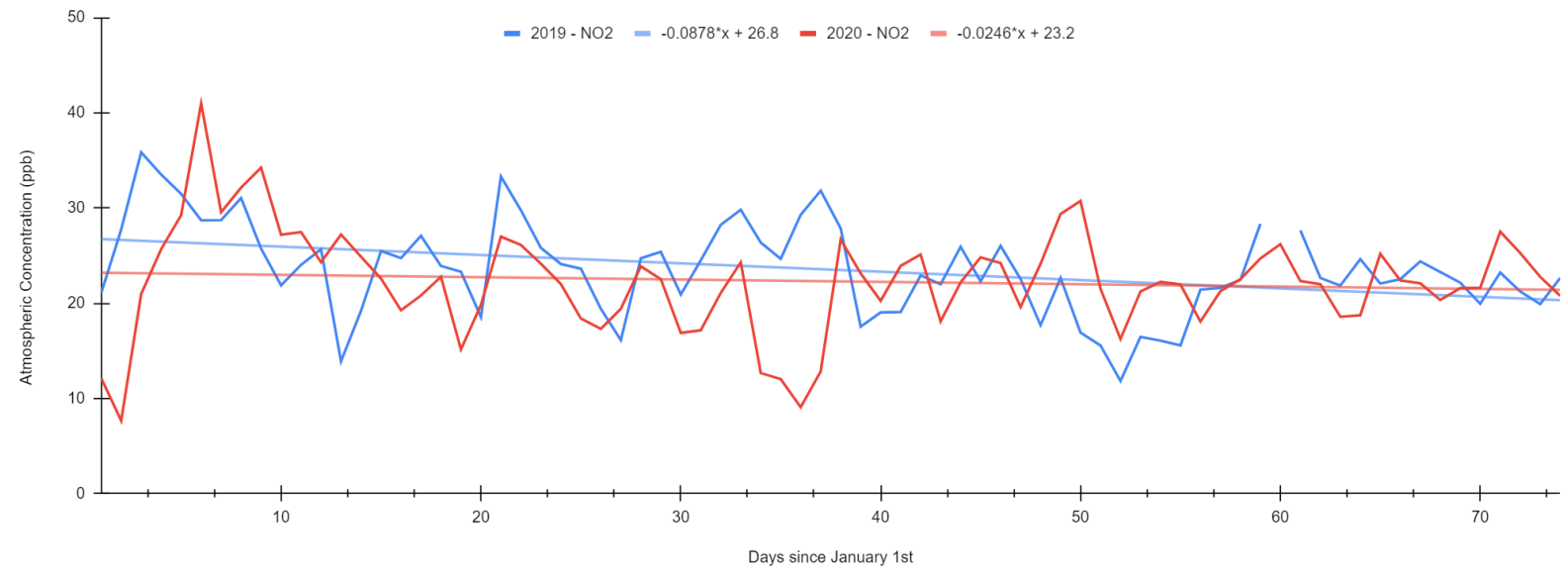

Figure 1. Graph of the daily averages of atmospheric concentrations in the city. Date shown in days since January 1. Own elaboration with data from the RAMA.

Looking at Figure 1, the 2020 concentrations were relatively lower during the beginning of the year. The percent difference between the beginning of this period and the end, the result is $-7.7 \%$ for 2020 and $-23.7 \%$ for 2019 . These numbers show that during this period of 2020 , there was a very low change in the atmospheric concentrations of $\mathrm{NO}_{2}$ but that in 2019 there was a more significant reduction. This can be verified with the slope of the regression lines, where that of 2019 has a value of -0.0878 and that of 2020 has a value of -0.0246 , showing that the trend in 2020 was more constant than that of 2019 - approximately 3.5 times flatter. However, the same cannot be said for the period from March 15 to December 31 . 
Daily averages of Nitrogen Dioxide in Mexico City from March 15 to December 31, 2020 and 2019

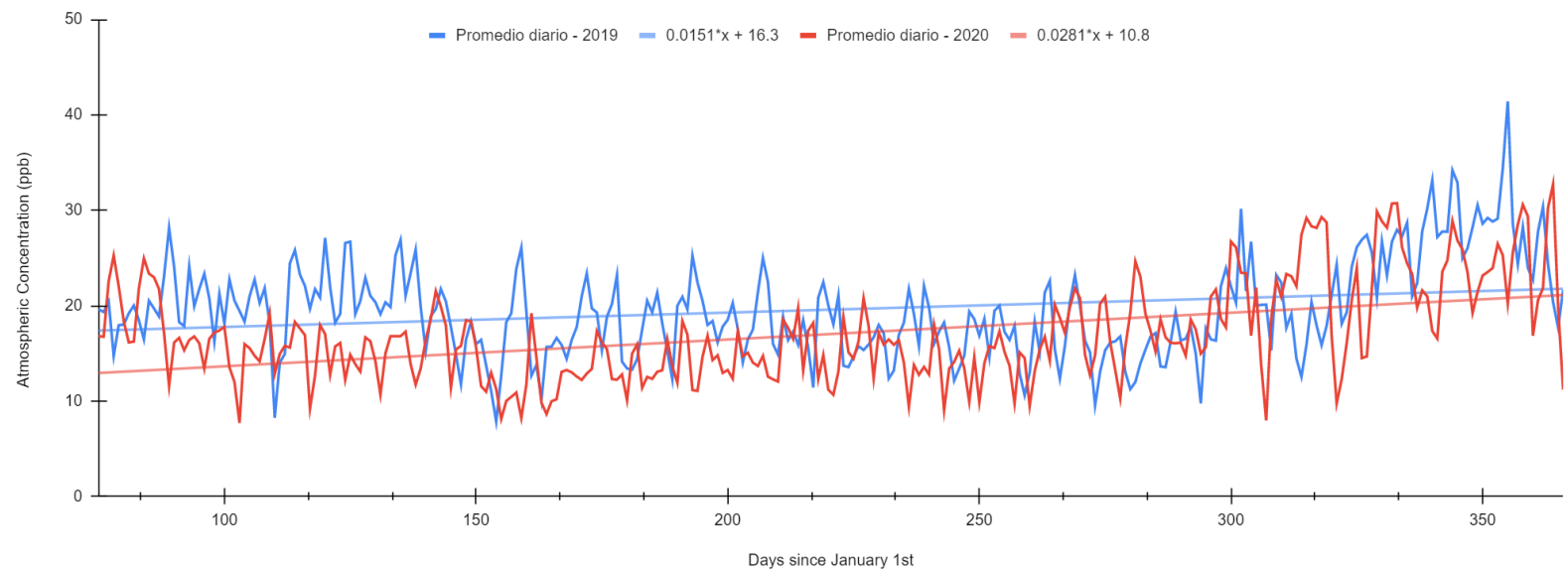

Figure 2. Graph of the averages of atmospheric concentrations in the city. Date shown in days since January 1 . Own elaboration with data from the RAMA.

Looking at Figure 2, there is a significant reduction in the concentration of $\mathrm{NO}_{2}$ in the atmosphere. As of March 15, 2019, there were approximately 17.4 parts per billion (ppb) of $\mathrm{NO}_{2}$ in the atmosphere while in 2020, the concentration was $12.9 \mathrm{ppb}$. Also, the equation for the 2020 regression line is $0.0281 * \mathrm{x}+10.8$. This line has an intercept on the vertical axis (10.8 ppb) much lower than that of 2019 (16.3 ppb). With this, it can be assumed that the restrictions on industrial activities and vehicular traffic had an impact on the release of $\mathrm{NO}_{2}$ gas. Although $\mathrm{NO}_{2}$ concentrations were lower during 2020 than during 2019, it is interesting to note that the regression line for 2020 had a considerably higher and positive slope: from 0.0281 while 0.0151 for 2019 . Additionally, the percentage change of the atmospheric concentration of $\mathrm{NO}_{2}$ (using the regression lines) during 2020 was $63.4 \%$ while during 2019 it was $25.2 \%$. As a result, at the end of the year, the average daily concentrations of 2020 are close to those of 2019. This is because on June 29, 2020, restrictions were reduced (change to the Orange Traffic Light) and industrial and traffic activities vehicles had fewer restrictions.

$4.2 \mathrm{O}_{3}$

Daily averages of Tropospheric Ozone in Mexico City from January 1st to March 14, 2020 and 2019

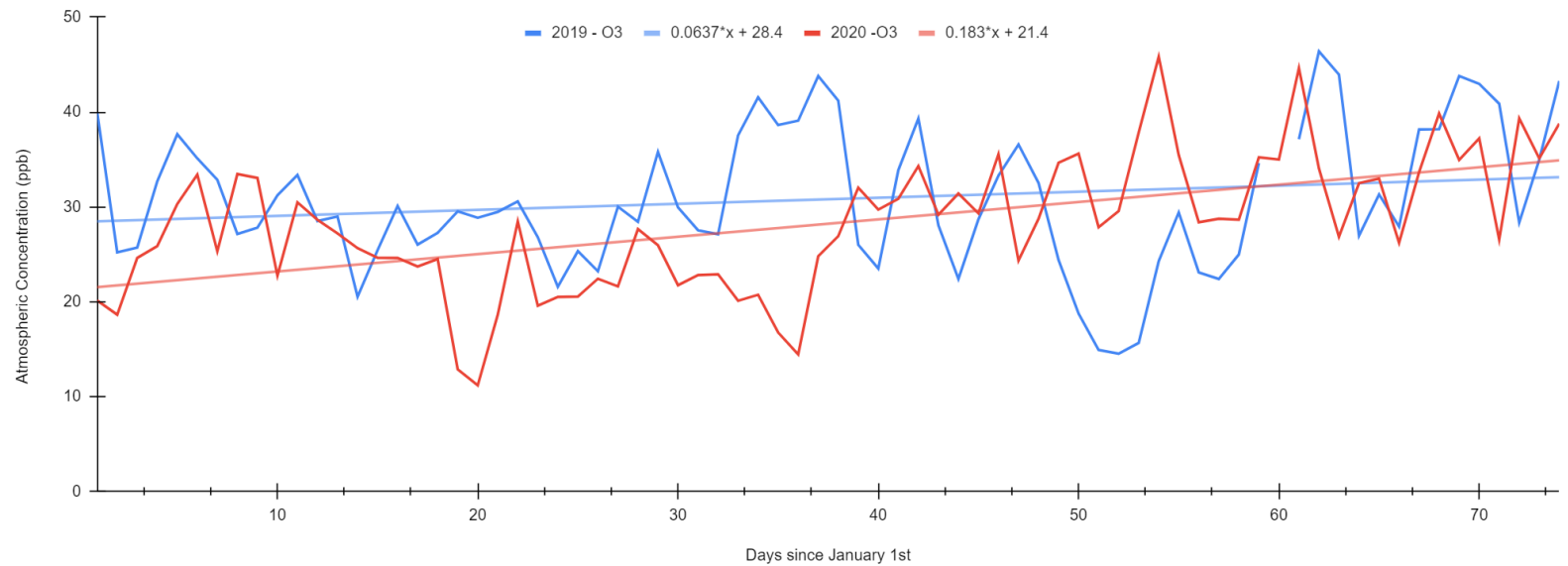

Figure 3. Graph of the averages of atmospheric concentrations in the city. Date shown in days since January 1 . Own elaboration with data from the RAMA. 
In Figure 3, the regression lines show that atmospheric $\mathrm{O}_{3}$ concentrations grew rapidly but were generally lower in 2020 than in 2019 for the first 50-60 days of the year. This is demonstrated by the slope of the regression lines, where the slope for the regression line of 2020 is 2.87 times steeper than that of 2019: for 2020, it was 0.183 and for 2019 , it was 0.0637 . This pattern can be explained as ozone is very sensitive to VOCs and solar radiation. Since VOCs are emitted by various products in the home and the beginning of the year is related to holidays, fewer ozone molecules were created due to the reduction in the use of household products and solar radiation. At the end of this period, people began to leave their homes less due to the pandemic, resulting in a reduction in NOx. This explains the increase in $\mathrm{O}_{3}$.

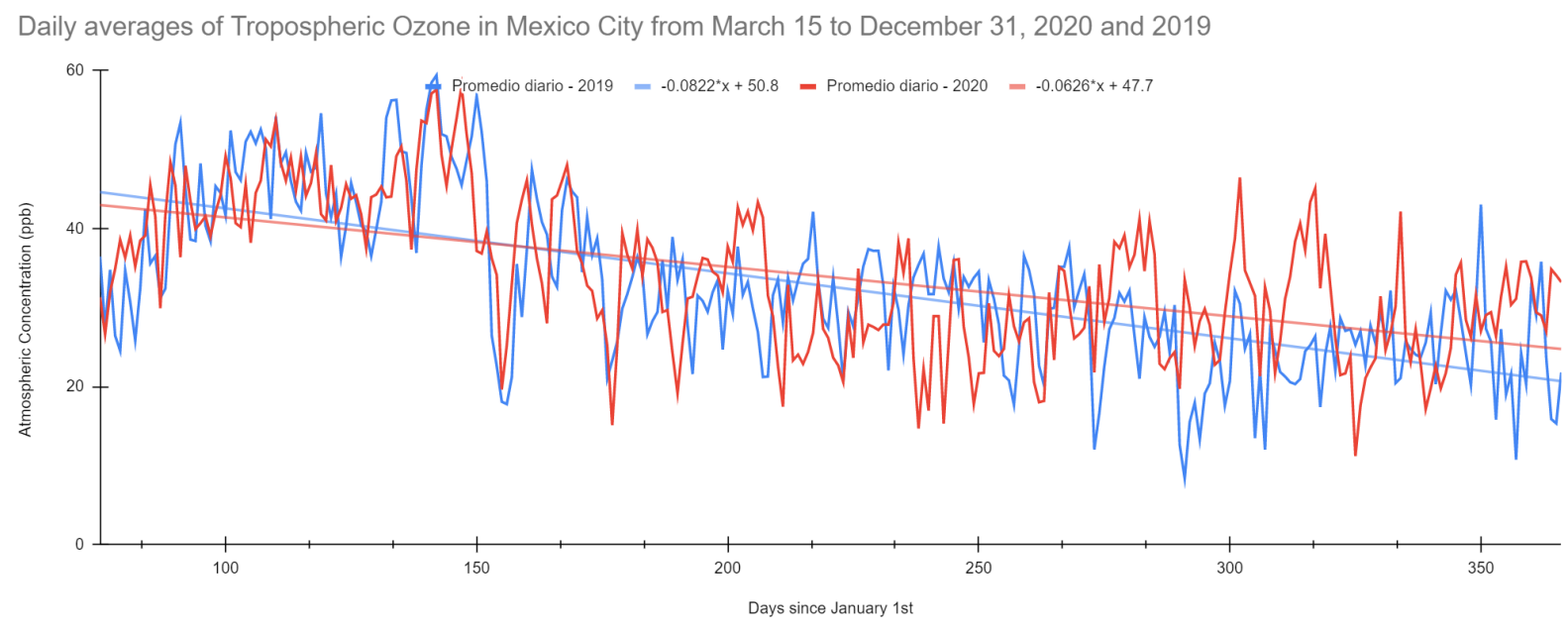

Figure 4. Graph of the averages of atmospheric concentrations in the city. Date shown in days since January 1 . Own elaboration with data from the RAMA.

Figure 4 shows us that the atmospheric concentrations of $\mathrm{O}_{3}$ in 2020 are initially lower than in 2019, but quickly exceed them. Because the pattern of fluctuations exhibited in 2020 is highly different from that exhibited during 2019 , it can be assumed that there were more important factors in the creation of tropospheric ozone in addition to vehicular traffic and industrial activities, since one would expect that concentrations of tropospheric ozone would reduce due to its dependence on fossil fuel combustion. In 2020, there was a reduction of 38.11\% while in 2019 it was $46.84 \%$; Furthermore, the slope of the regression line for this period during 2020 was -0.0626 , which has a less pronounced slope than that of 2019 of -0.0822 . This shows that the reduction in atmospheric ozone concentration was more significant during 2019.

\subsection{Relationship with Acute Respiratory Diseases}

The studied pollutants have a great impact on human health as they irritate the respiratory tract and aggravate existing respiratory diseases in the respiratory system. For example, exposure to $\mathrm{NO}_{2}$ strongly aggravates bronchitis. Table 2 displays a complete list of acute respiratory diseases.

Table 2. Acute respiratory diseases included in the Epidemiological Bulletin of the Government of Mexico by code.

\begin{tabular}{cl}
\hline Code & \\
\hline J00 & Acute nasopharyngitis \\
J01 & Acute sinusitis \\
J04 & Acute laryngitis and tracheitis
\end{tabular}


J06 Acute multi-site or unspecified upper respiratory infections

J20 Acute bronchitis

J21 Acute bronchiolitis

Something interesting in Table 3 is that pollutants exhibited a more prominent reduction during 2019. This is because the 2020 regression lines were considerably more consistent (flat), which means that the medians of atmospheric concentration of the pollutants experienced less variability throughout the year. However, it should be noted that although a lesser reduction was exhibited during 2020, atmospheric concentrations of $\mathrm{NO}_{2}$ were significantly lower throughout the year, which means that the restrictions imposed by Mexico City's government played an important role in the reduction of daily maximum $\mathrm{NO}_{2}$ concentrations in 2020 compared to 2019 .

Table 3. Percentage change during the year of $\mathrm{NO}_{2}, \mathrm{O}_{3}$, and number of infections from acute respiratory diseases.

\begin{tabular}{cccc}
\hline Year & $\mathrm{NO}_{2}(\%)$ & $\mathrm{O}_{3}(\%)$ & Acute respiratory disease infections (\%) \\
\hline 2019 & -6.02 & -31.44 & +787.59 \\
2020 & +0.25 & -15.69 & +596.16
\end{tabular}

The pattern exhibited in Figure 5 may have been influenced by social restrictions, vehicular traffic, and industrial activities since the reduction of human contact reduced the number of infections. During 2019, the increase in patients with acute respiratory diseases was significantly higher than in 2020: 129,546 new cases every 4 weeks during 2019 and 73,406 during 2020. Seeing Table 3, there was an increase of 787.59\% for 2019 and $596.16 \%$ for 2020. In addition, in week 52, the number of infections in 2019 was $65 \%$ higher than in 2020 . These values show that although the number of infections of acute respiratory diseases in week 4 of 2020 and 2019 were very similar, the increase in these infections was significantly higher during 2019.

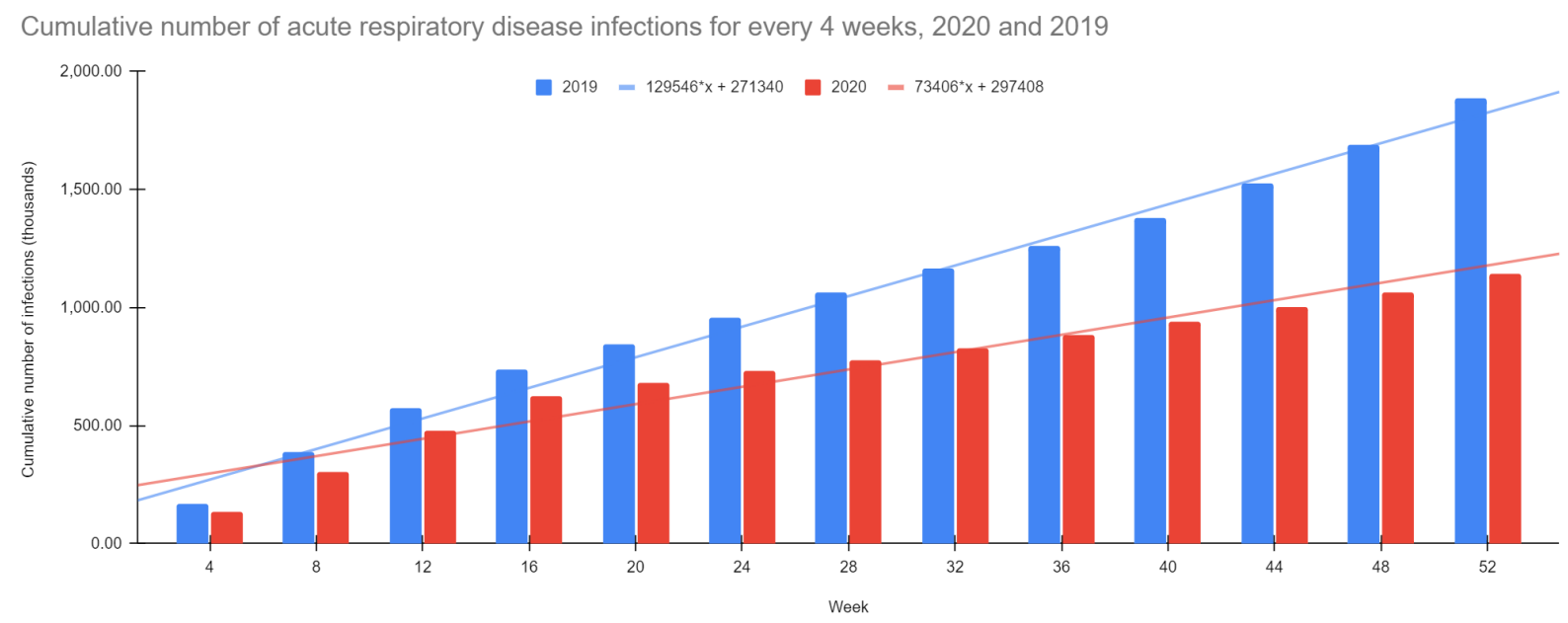

Figure 5. Bar graph of the accumulated number of acute respiratory disease infections (excluding COVID-19) in Mexico City for every 4 weeks. Own elaboration with data from the Epidemiological Bulletin of the Government of Mexico. 
As mentioned, the pollutants analyzed in this research aggravate respiratory diseases, but they do not cause them. This means that decreasing atmospheric concentrations of the gases described above reduced the aggravation of existing acute respiratory illnesses for millions of people. So, it can be concluded that the reduction in the concentrations of these pollutants positively affected people with existing respiratory diseases since the improvement in air quality prevented the aggravation of their symptoms and prevented them from requiring hospital care, resulting in a reduction in the number of patients with acute respiratory diseases in Mexico City.

\section{Conclusion}

In this study, the daily averages of $\mathrm{NO}_{2}$ and $\mathrm{O}_{3}$ were analyzed. For $\mathrm{NO}_{2}$, there was a significant reduction in the second period of time studied, while $\mathrm{O}_{3}$ exhibited the opposite due to the reduction of NOx (in this case $\mathrm{NO}_{2}$ ). As ozone is a secondary pollutant, it is the reduction in VOCs that would cause a reduction in atmospheric ozone concentrations, not a reduction in NOx. However, the reduction of $\mathrm{NO}_{2}$ (see Table 1) was enough to conclude that the general air quality in the City improved, which resulted in fewer people hospitalized for acute respiratory diseases in 2020 compared to 2019 (see Figure 5). So, it can be concluded that the contingency period caused by the recent COVID-19 pandemic resulted in a reduction in atmospheric concentrations of the pollutants studied and in a reduction in the number of people hospitalized for acute respiratory diseases related to these pollutants.

\section{Acknowledgements}

José Carlos Alaniz from the Department of Science of the American School Foundation, A.C. for his help and guidance throughout the research process.

Dr. Mónica Jaimes Palomera from the Atmospheric Monitoring Directorate of Mexico City for her help during the collection and processing of data.

\section{References}

Gobierno de México. (2020, enero 06). Boletín Epidemiológico de México 2019. Boletín Epidemiológico Sistema Nacional de Vigilancia Epidemiológica Sistema Único de Información. https://www.gob.mx/salud/documentos/boletinepidemiologico-sistema-nacional-de-vigilancia-epidemiologi ca-sistema-unico-de-informacion-2019

Gobierno de México. (2021, febrero 08). Boletín Epidemiológico de México 2020. Boletín Epidemiológico Sistema Nacional de Vigilancia Epidemiológica Sistema Único de Información. https://www.gob.mx/salud/documentos/boletinepidemiologico-sistema-nacional-de-vigilancia-epidemiologi ca-sistema-unico-de-informacion-231750

Gobierno de la Ciudad de México, Calidad de Aire. (n.d.). Aire CDMX. http://www.aire.cdmx.gob.mx/

Gobierno de la Ciudad de México, Calidad de Aire. (n.d.). Dirección de Monitoreo Atmosférico. Bases de datos Red Automática de Monitoreo Atmosférico (RAMA).

http://www.aire.cdmx.gob.mx/default.php?opc $=\% 27 \mathrm{aKBh} \% 27$ 